\title{
Funciones de integración del Estado
}

\author{
Oscar Godoy A. \\ Instituto de Ciencia Politica \\ Pontificia Universidad Católica de Chile
}

\begin{abstract}
El discurso y la práctica del Estado moderno nos revelan que una de sus funciones principales es la integración nacional. En este trabajo, centrado en el caso chileno, se toma como punto de partida al Estado integrador moderno, para analizar los conceptos centrales que dan cuenta de la función estatal de integración y las grandes líneas de su evolución y actual situación en nuestro país. A estos efectos, la exposición del tema está articulado en dos capítulos, que tratan acerca de la concepción y prácticas tradicionales del Estado integrador, por una parte, y el estado actual de la función de integración nacional, en el contexto democrático y pluralista de los tiempos presentes, por otra.
\end{abstract}

\section{EL DISCURSO CLÁSICO DE LA INTEGRACIÓN ESTATAL}

\section{Algunas consideraciones normativas sobre el Estado y la integración}

Desde la perspectiva discursiva, puramente teórica o normativa, la integración está relacionada con el hecho que el Estado, o la sociedad políticamente organizada, le confiere unidad a una comunidad humana en un territorio determinado. En consecuencia, la integración expresa el efecto articulador y coherencial primero del Estado, que configura o da forma a una comunidad política. Sin esta acción del Estado, tal comunidad no existiría, pues sus miembros serían individuos dispersos y débilmente vinculados entre si. Por esta razón, algunos suponen que toda comunidad, antes existir como todo organizado bajo la forma de Estado, es una masa informe. De este modo, se concluye que el Estado, a través de instituciones, leyes, normas y prácticas comunes, organiza e integra individuos dispersos; configura y da unidad e identidad a un pueblo, establecido en un territorio, a través del tiempo. Dicho de otro modo, estamos hablando de una acción colectiva que unifica, o sea, que reduce una multiplicidad a una unidad política. Este acto, a la vez, le confiere identidad a la comunidad. Pero, no una identidad abstracta, sino una identidad concreta e histórica, que posee espacialidad territorial, se despliega en el tiempo y permite la identificación de un pueblo en el concierto de las naciones.

Ahora bien, ¿en que consiste ese acto que da unidad, identidad, identificación y organización a una agrupación humana? Es el acto por el cual una comunidad asume la responsabilidad de gobernarse a si misma, sin dependencia a un tercero. 0 sea, en forma autónoma. A esta dimensión de una comunidad que se autogobierna, se la denomina soberanía, cuya formulación más clásica dice así: potestad o poder absoluto y perpetuo de gobernarse a si mismo un pueblo ${ }^{1}$ y cuando ello ocurre, en sentido histórico, la comunidad que ejerce esa facultad tiene o es un Estado. Por lo 
tanto, la independencia y la autonomía son elementos esenciales del Estado, como un supuesto a partir del cual una comunidad adquiere unidad, identidad y organización. Y estos, a su vez, son las bases de las instituciones, las leyes y las prácticas.

Cualesquiera sea el origen del Estado - un pacto, un acto unilateral, un proceso evolutivo espontáneo, etc., la unidad de una realidad compleja, como es el caso de la sociedad políticamente organizada, no se mantiene cohesionada solamente por un espíritu común de solidaridad, un consentimiento básico, costumbres ancestrales compartidas por todos y leyes aceptadas por la comunidad, sino también por el ejercicio monopólico de la coerción. El Estado de suyo necesita poseer un potente dispositivo de fuerza para defender su soberanía, la existencia y despliegue de las instituciones, el imperio de la ley y la integridad territorial, frente a un eventuales agresores externos y trasgresores internos, que podrían poner en peligro su continuidad y estabilidad.

Pero hay una variable adicional que debe ser considerada. Ningún Estado existe sin adoptar la forma de un régimen político. En nuestro caso, ese régimen es la democracia representativa. Por lo tanto, cuando hablamos de la función integradora del Estado, no podemos hacerlo sin referirnos a los efectos cohesionadores y articuladores de la sociedad chilena que fluyen de su propio régimen democrático. Pero, la democracia, además de ser un modo de organizarse el Estado, es también un complejo sistema de vida, que requiere condiciones propias y difíciles de realizar. Entre ellas, un tipo específico de integración política, a la cual nos referiremos más adelante, y que adquiere la plenitud de su significado en el siglo XX.

Todo lo anterior significa, en suma, que hay efectos integradores atribuibles, por un lado, al Estado propiamente tal, y, por otro, a la democracia como régimen político y sistema de vida social.

El tema que quiero abordar en este texto se refiere a la práctica estatal chilena y sus efectos integradores. La estructura del trabajo se ciñe a las tres líneas de integración que acabamos de enunciar.

\section{LAS PRÁCTICAS INTEGRADORAS CLÁSICAS DEL ESTADO CHILENO}

Al hablar de integración, podemos suponer que el hecho de habitar un espacio común, la vecindad espacial y la observancia de ciertas prácticas consuetudinarias de vida comunitaria, constituyen las bases primarias de la integración. Pero más allá de esta realidad originaria, parece evidente que el acto de integración fundacional es la independencia, como decisión de autonomía, en nuestro caso, de la Corona española. Y ello, en virtud de que a través suyo, los chilenos tomamos la decisión de organizarnos y cooperar entre nosotros como Estado soberano. 0 sea, como una comunidad política que se gobierna a si misma.

\section{Integración política, elite y sociedad civil}

No obstante, hay que tener presente que Chile era ya una comunidad integrada, con formas jurídicas estatales, antes de su independencia; pues, en efecto, era gobernada por una potencia europea, bajo un régimen de dependencia política a la Corona española. La historiografía establece algunos vínculos de continuidad entre esas formas y el Estado chileno, que no es el caso tratar 
extensamente aquí. Pero, de un modo sumario, el acento de esas continuidades están puestas sobre la existencia de una sociedad civil ya constituida. Acerca de ella, Alberto Edwards, por ejemplo, enfatiza las siguientes características que se resumen brevemente: (1) su homogeneidad, con predominio racial blanco, que "tempranamente logró absorber el elemento indígena" 2 (Barros Arana supone que a fines del siglo XVII "la fusión de razas estaba casi totalmente consumada al norte del Bío-Bío"); (2) el predominio de una clase alta, propietaria de la parte más rica y poblada del territorio (des de Illapel hasta el Maule); (3) no existencia una clase social media, que le sirviera de contrapeso "ni remotamente, al poder de la aristocracia" ${ }^{3}$.

El mismo autor, también se refiere a otras particularidades chilenas que son relevantes para la constitución de una sociedad civil organizada: "un espacio reducido, cuyo clima y producciones eran singularmente homogéneos" . Estos factores son decisivos para asegurar a la "alta sociedad", nos dice Edwards, su dominación "de un país pequeño, a que el mar y su valle longitudinal proporcionaban comunicaciones fáciles". Ello facilitó que esta elite no tardara "en adquirir unidad y cohesión"5.

No obstante, la visión de Edwards se refiere a la sociedad civil chilena en forma incompleta, porque su análisis se limita a explicarnos la emergencia de la elite chilena colonial, que lidera posteriormente la independencia de la Corona española. Esta visión limitada simplifica la compleja trama de la sociedad civil chilena, dejando en la penumbra el mestizaje y la variedad étnica y cultural que forman parte de la base social. Edwards es un buen ejemplo de una historiografía y de una interpretación socio cultural que privilegia solamente una variable de la génesis de la sociedad civil chilena, a expensas del resto. Esta perspectiva reductora tiene su explicación, e incluso su justificación, sobre el supuesto que aquello que hay que explicar es el protagonismo de una elite en la constitución del Estado chileno. Pero, como veremos, más adelante, el reduccionismo de Edwards no permite explicar satisfactoriamente las bases de una sociedad democrática pluralista ni tampoco la función integradora de un Estado democrático bajo la condición del pluralismo societal.

\section{Independencia nacional e integración}

La adquisición de autonomía soberana chilena va precedida de una cierta configuración histórica de la sociedad civil que le sirve de base. De acuerdo a lo que llevamos dicho, en esa configuración tiene un rol determinante la elite colonial, en el sentido que ella es un factor esencial de integración política, económica y cultural. Si ponemos entre paréntesis los poderosos efectos integradores de la Corona española, como poder omnipresente, a través las facultades soberanas de sus monarcas, en el ámbito de la ley y la administración imperial, es fácil establecer la función de integración que ejerció la elite que concentraba el ejercicio del poder político local, y, además, la riqueza, cuya base es la propiedad agrícola, y la administración de las instituciones de la cultura oficial. 
No obstante, más allá de las formas institucionales de la cultura - la escuela, la Universidad, el cultivo de las artes y las letras bajo el patrocinio real, etc.- la lengua y la religión ejercen una causalidad integradora que podríamos denominar supraestructural. La expansión del español y la aparente desaparición, o extinción virtual, de las lenguas indígenas, constituyen un factor esencial de la integración del país, que se expresa de modo predominante, en el habla cotidiana, de sur a norte, en este idioma, y que, en las comunicaciones oficiales, lo debe hacer y lo hace de un modo absoluto. En la práctica, el resultado es una hegemonía casi total de esta lengua. Y lo mismo puede decirse de la religión católica, no solamente porque es la religión oficial de la monarquía hispana, durante todo el período de constitución de la sociedad civil, sino también del Estado chileno durante un extenso período de la República. Unión de la Iglesia y el Estado. A lo cual hay que agregar su enorme fuerza moral, su energía civilizadora y su poderosa capacidad persuasiva. Tanto el idioma, como la religión católica, son vehículos de una cultura, que frente a las culturas autóctonas, tiene el aura de constituir un nuevo y superior desarrollo del género humano.

En consecuencia, el acto de fundación del Estado no se hace a partir de cero. La historia actúa en este caso como una fuerza tradente, a través de la cual discurren flujos de continuidad, que asumen formas variadas. Pero ese acto fundacional expresa una discontinuidad, en el sentido que es expresión de la voluntad de desarrollar un nuevo proyecto de vida política. En todos los casos modernos de creación de un Estado, la discontinuidad consiste en la ruptura con algún tipo de dependencia y en el comienzo de una existencia independiente. No somos una excepción, pues, nuestro caso particular consistió en la decisión de asumir la soberanía, e independencia de nuestros lazos con la monarquía española, bajo la forma política republicana, en el período 1810-1833.

Este hecho fundamental consiste en que nos hicimos cargo de nuestro propio destino, como nación independiente y Estado soberano. De él, a su vez, se proyecta la emergencia de otra realidad nueva: la adopción del sistema republicano y del régimen presidencialista (cuyo modelo fue el presidencialismo norteamericano). Ahora bien, el sujeto o identidad política que toma la decisión de realizar la independencia y poner en marcha el Estado y el sistema republicano es la clase dirigente chilena. 0 sea, una elite. Y esa elite escogió un régimen que incluía el estado de derecho, la división de poderes y un sistema representativo restringido, pero no el sufragio universal, ni la participación ciudadana extensa, ni el control ciudadano sobre los órganos del Estado. En efecto, el sistema republicano del siglo XIX no es democrático y es funcional a un predominio de la minoría ilustrada sobre las mayorías. Por esta razón se puede sostener que la elite escogió un sistema conforme "a" y funcional "sus" intereses. Y a efectos de confirmar esta tesis, basta con hacer una referencia a Diego Portales, fundador de la República, y las razones que adujo para postergar el advenimiento de la democracia.

El talento de le elite fundadora consistió en conservar la unidad necesaria para darle gobernabilidad al país y consolidar sus instituciones básicas: la presidencia, el parlamento y la judicatura. En este sentido, se puede decir que la primera actividad integradora del Estado republicano chileno fue extraordinariamente exitosa. Bajo otra óptica se puede afirmar que la condición primera y necesaria para la integración, que era cimentar su propio fundamento, o sea, establecer el Estado, fue plenamente cumplida. A partir de esta instancia, Chile adquiere una identidad clara y distintiva, como consciencia de si mismo, y, a la vez, como una nación organizada en el escenario internacional. En definitiva, se produce la integración política fundamental. 


\section{Integración territorial y ius belli}

No obstante, durante un período relativamente extenso, esa identidad política une a una sociedad civil que habita un territorio cuyos límites no están claramente definidos. La primera definición territorial marca la situación dominante de la elite sobre la sociedad civil. Eso acontece entre el Maule y el Bío-Bío. Fuera de esta extensión territorial, en la práctica hay comunidades con arraigos locales, pero no hay propia y estrictamente sociedad civil chilena. El Estado republicano no es el correlato político, articulador y coherencial de esas comunidades dispersas al norte de Illapel y al sur del Bío-Bío. En consecuencia, durante gran parte del siglo XIX, el Estado, que por tener su capitalidad en el centro geográfico del país, pasa a denominarse central, despliega una obra sistemática de integración territorial. Este despliegue se realiza por dos vías: el ejercicio actual de la soberanía sobre territorios que estaban bajo su jurisdicción soberana virtual (zona de Arauco, Chiloé, Magallanes) y la expansión territorial por vía de la conquista militar (Tarapacá y Antofagasta).

En este punto hay que ponderar el rol que han jugado la fuerza o capacidad de coerción del Estado chileno. Y tomar en cuenta que la historiografía chilena ha enfatizado, como una de las características de la constitución de la sociedad civil chilena, la constante presencia de las fuerzas armadas en el escenario público del país. Para Edwards Vives, por ejemplo, la existencia de una frontera bélica en Araucanía, creó las condiciones para el desarrollo de un centro militar aristocrático en Concepción, que tuvo un rol importante en la configuración de Chile. La existencia de esta elite involucró la disponibilidad, por parte del Estado, de una organización y unas prácticas bélicas sostenidas durante siglos. Mario Góngora, por su parte, le atribuye a las fuerzas armadas, y su protagonismo en la llamada pacificación de la Araucanía y en las dos guerras contra Perú y Bolivia una función determinante en la consolidación del Estado y la nacionalidad chilena ${ }^{6}$. En esta perspectiva, hay que incluir como elementos integradores, tanto los factores de diferenciación, hacia afuera, y de identificación, hacia adentro, que entraña el establecimiento de las fronteras que acotan el territorio nacional, como, por su fuerte connotación comunitaria y productora de símbolos, la participación de la población en guerras contra un enemigo exterior ${ }^{7}$. En este punto, conviene destacar que la extensión de la soberanía a la Araucanía marca un hito en el uso de la fuerza como un factor de integración coercitiva. La llamada pacificación tiene las características de una guerra exterior, pero se realiza en un territorio que el Estado consideraba bajo su jurisdicción soberana, tal como lo había concebido el gobierno colonial (bajo la soberanía de la monarquía, y, por ende, bajo la jurisdicción política local de la Capitanía General de Chile). Sin embargo, como es sabido, la etnia mapuche siempre entendió su derrota como una invasión y una conquista, sin ceder su poder de auto-gobierno.

La aplicación del poder coercitivo, cuyo monopolio detenta el Estado, a la determinación de los límites del territorio y al ejercicio de su poder soberano en toda su extensión, por una parte, y la creación de una autoidentificación nacional, por otra, han sido elementos clásicos de integración.

6 Góngora, Mario, Ensayo Histórico sobre la Noción de Estado en Chile en los Siglos XIX y XX ; Editorial Universitaria, Santiago, 1986; p. 29 a 38.

7 Campos Harriet, Fernando, Historia Constitucional de Chile, Editorial J urídica de Chile, Santiago, 1956. En esta obra, Campos Harriet, al explicar la guerra contra la Confederación Perú Boliviana, dice lo siguiente: "Esta guerra formó en Chile, el sentimiento de patriotismo. Hasta entonces, aun los más destacados próceres de la Independencia se sentían americanos, sin fronteras. El mismo 0’Higgins no miró con buenos ojos desde su destierro en Montalván, esta guerra que estimaba fratricida" (p.231) 
Pero, como es evidente, este fenómeno no es determinante en la conformación de la nacionalidad y de la nación, como identidades integradoras. En efecto, como veremos, la nación se constituye en un polo magnético de atracción espiritual y moral en las sociedades modernas, suscitando un fuerte arraigo y actuando como un elemento racional y afectivo de unidad, que sobrepasa la mera actividad soberana y el puro ejercicio de la guerra. A lo largo de este trabajo, hemos visto el carácter coherencial primero que tiene el Estado, como poder de autogobierno de la sociedad civil, y los efectos integradores que tiene en Chile una de las actividades que fluyen de la soberanía: el ejercicio del ius belli. Pero, aunque estos factores son necesario para explicar la unidad del país, y, por lo mismo, una de las bases seminales de la nación, no son suficientes para dar cuenta de la aparición de la nación misma y del sentido de nacionalidad.

\section{La identidad nacional}

El surgimiento del Estado en las sociedades modernas ha convertido a estas últimas en naciones. La incidencia de este cambio en el discurso de la integración estatal es muy claro. Antes que surgiera el estado moderno, existía un concepto débil de nación, que no se superponía al de sociedad civil. Hoy, en cambio, la sociedad civil chilena es, a la vez, en gran parte aunque no enteramente, la nación chilena (el discurso nacional no es participado por todos los que jurídica y formalmente son considerados chilenos, incluso se advierte un incipiente planteo soberanista en sectores radicales de la etnia mapuche). Esta nueva noción, por otra parte, ha producido desplazamientos y substituciones conceptuales importantes en la teoría y la práctica constitucional, como la indican las dos versiones de la soberanía: nacional, por una parte, popular o del pueblo, por otra.

Con anterioridad a la aparición de los Estados, el término nación designaba el lugar de origen y pertenencia, y también a las personas que habiendo nacido en un lugar, pero habitando en otro, acostumbraban a asociarse en una corporación para adquirir una identidad específica. La existencia de las nationes en la Edad Media carecía de significación política. Ellas eran una de las tantas corporaciones, como las universidades y los distintos gremios, que formaban parte del conjunto europeo de la Cristiandad. Esta situación cambia sostenidamente a medida que empiezan a aparecer los nuevos Estados. En la transición hacia esa nueva situación, los habitantes, bajo la autoridad del nuevo príncipe, se van identificando gradualmente con un sentido de comunidad y de identidad de la que carecían en el pasado (y que era, en cierta medida, contradictoria con la pertenencia genérica a esa vasta comunidad que era la Cristiandad). De este modo, se reconstruye el concepto de patria y se arraiga y difunde una relación de reciprocidad entre la nueva monarquía y la comunidad ${ }^{8}$.

De este modo, se puede decir que hay un proceso de construcción de las naciones, que es anexa 0 acompaña a la del Estado, aunque en algunos casos se da el hecho que una etnia no-dominante desarrolla una identidad nacional y reivindica para si el autogobierno ${ }^{9}$, o sea, demanda la independencia para organizarse como Estado nacional. El caso de Chile no corresponde a esta segunda 
clase de construcción estatal, sino a la primera, aunque con matices diferenciales propios. La comunidad o sociedad civil que se organiza al interior del Estado chileno sigue un proceso que culmina en la constitución de una nación. Así, el autogobierno es un atributo de una comunidad de los que nacen en el territorio en que ella existe y de todo aquello que le confiere unidad: religión, lengua, historia, costumbres; pero, de modo creciente, las leyes escritas, la tributación y la posesión de ejércitos. Y el ejercicio de una serie de actividades que se siguen de las posesión de tales atributos: darse leyes, gobiernos y jueces; hacer la guerra, etc. El sujeto colectivo que posee las características anotadas y que tiene presencia como un actor entre actores es a la vez un Estado y una nación.

La nación y la nacionalidad, en consecuencia, son construcciones del Estado moderno ${ }^{10}$. En Chile esta tarea constructivista se realiza a partir de una materia prima, a la cual hemos aludido, y que es la sociedad civil. Pero es claro, que esa sociedad civil, con anterioridad al surgimiento del Estado, no se identifica a si misma como la nación chilena. 0 sea, ella no tiene autoconciencia de una identidad nacional y por lo mismo, los habitantes del territorio colonial no se perciben y entienden a si mismos como miembros de una comunidad nacional chilena. A nivel de la sociedad civil hay una pluralidad de identidades, relacionadas con el lugar en que se vive (en un sentido local inmediato: santiaguinos, serenenses, pencones, etc. $)^{11}$, el sector social propio, la etnia la cual se pertenece, el territorio en el cual se habita; y, también, como trasfondo a la relación con la Corona española, la religión, la lengua, etc. Se carece, en definitiva, de una identidad que abarque y de sentido de pertenencia a una sola nación. Esa identidad y autoconciencia se construye a partir del Estado durante el siglo XIX.

Hay que agregar, como un elemento que fortalece nuestra argumentación, que no se puede sostener que en Chile la nación hubiera estado prefigurada en una etnia ${ }^{12}$. Y que, en consecuencia, el desarrollo de la nación y la nacionalidad chilena fueran el producto de una evolución resultante en un Estado nacional étnico. No es así. La construcción de la nación y la nacionalidad por el Estado, sobre bases no étnicas, es similar en su diseño a aquella que pretendieron los constituyentes de las Cortes de Cádiz, a nivel de todo el imperio. En efecto, para los constituyentes, reunidos en esas Cortes, "La Nación española es la reunión de todos los españoles de ambos hemisferios". Y se considera miembros de la nación española y, por lo mismo, españoles, al conjunto de los "hombres libres nacidos y avecindados en los dominios de las Españas, y los hijos de éstos"13. En el trasfondo de esta idea de nacionalidad no hay una concepción étnica, sino una concepción jurídico política, que emana de la voluntad del Estado. Este es el modelo que van a aplicar la mayor parte de los nuevos Estados americanos durante la Independencia. De este modo, la integración nacional no va a tener, como punto de despegue, una concepción étnica, sino una idea de pertenencia a una comunidad unida en torno a los principios políticos establecidos en la Constitución y

10 Góngora, Mario, op. cit. ; se refiere a nuestro caso en los siguientes términos: "La nacionalidad chilena ha sido formada por un Estado que ha antecedido a ella, a semejanza, en esto, de la Argentina; y a diferencia de México y del Perú, donde grandes culturas autóctonas prefiguraron los Virreinatos y las Repúblicas"; p. 37. En este texto se da por supuesto al menos dos modos distintos de originarse la nación y la nacionalidad.

11 Góngora, Mario, op. cit. ; "Durante la Colonia se desarrolla un sentimiento regional criollo, un amor a "la patria" en su sentido de tierra natal, de que nos dan amplios testimonios los cronistas, como Alonso Ovalle y los jesuitas expulsos en Italia, etc. ", p. 37.

12 Smith, Anthony D., The Ethnic Origins of Nations, Blackwell Publishers Ltd., Oxford, Malden (Mass.), 1988.

13 Constitución Política de la Monarquía Española (llamada Constitución de las Cortes de Cádiz de 1812/, Título I, art. 1 y Título II, art. 5, primero. 
la implantación territorial de la misma. Más tarde vendría la nación y la nacionalidad, tal como la entiende el nacionalismo romántico de Herder, por ejemplo.

\section{La integración a través de la constitución, la ley y las instituciones políticas republicanas}

El Estado chileno se organiza como un república. A través de una constitución escrita (1833), adopta como principio arquitectónico de sus instituciones, los principios de soberanía nacional y de representación. La soberanía, dice su artículo cuarto, "reside esencialmente en la nación que delega su ejercicio en las autoridades que establece esta Constitución"14.

En el proyecto se establecía que la soberanía residía en el pueblo. Pero, el término "pueblo" fue substituido por el de "nación" después de un debate en que se dejaron establecidas las aprehensiones que suscitaba el uso de la palabra pueblo, se marcó una preferencia por el concepto de nación ${ }^{15}$. En esta simple substitución está expresado el debate de ideas mantenido desde la revolución francesa, y durante todo el siglo XIX, alrededor de los conceptos de pueblo y nación. No corresponde reproducir en este trabajo esa discusión. Solamente verificar que en tiempos de la Independencia prevalece el término nación, entre otras razones porque es más funcional a un sistema representativo basado en una ciudadanía restringida. En efecto, mientras el principio de "soberanía popular" supone una ciudadanía amplia y el ejercicio del voto universal, el principio de "soberanía nacional" permite que los representantes, elegidos por una ciudadanía limitada y el voto censitario, siempre "representen al todo de la nación", en la acepción acuñada por Sieyès durante el proceso revolucionario francés ${ }^{16}$

La Constitución de 1833 consagró libertades y derechos individuales, la supremacía constitucional y la división de poderes. De este modo, el país adoptó el dispositivo básico del Estado de derecho moderno. Y se puede decir que tanto por la fuerza discursiva de estas bases, como la práctica sostenida de las mismas durante mas de 180 años, ellas conforman los "esenciales constitucionales" ${ }^{17}$ del país. Estos esenciales, y todo el aparato institucional y jurídico fundado en ellos, ha actuado como un factor de integración cultural y política del país.

De este modo, el régimen político mis mo ha tenido una fuerte incidencia en la integración del país. Tempranamente, dicen los historiadores y los analistas políticos, Chile tuvo un "Estado en forma". Hay que agregar: y también un régimen republicano estable y suficientemente bien organizado como para darle gobernabilidad al país. A pesar de los accidentes o turbulencias políticos mayores, como la revolución de 1890 y el gobierno militar de 1973, los esenciales constitucionales han constituido un dinamismo de continuidad e identificación del país, mostrando así su fuerte potencial integrador.

Ahora bien, esta función integradora del régimen político republicano tiene una especial significación. Ella, en cierta medida, como veremos más adelante, compite con la función integradora del sentido nacional. $Y$, en esa competencia, se va a hacer patente un soterrada y sigilosa contienda 
entre el nacionalismo, que se despliega a partir de la idea y la realidad de la nación, y la democracia del siglo XX, como heredera y ulterior desarrollo del régimen republicano decimonónico. Esa contienda, va a cobrar distintas formas, a lo largo del tiempo. Pero, en el presente, creo que se plantea el tema de qué pertenencia es prevalente -cuando realizamos tardíamente que Chile es un país multiétnico, irreductible a una sola nación en sentido étnico- , o sea, la pregunta acerca de la prioridad de la pertenencia a la nación o al sistema político.

\section{La integración económica}

Las primeras medidas del nuevo Estado chilena, en el ámbito económico, estuvieron orientadas a crear las condiciones para permitir el libre cambio, proteger la agricultura nacional y promover la creación de la industria. Todas ellas se ciñen a los patrones del neo-mercantilismo español del siglo XVIII, que era la tendencia predominante en la elite chilena. La adopción de la escuela clásica y del mercado se produce en la segunda mitad del siglo XIX. Especialmente con la difusión de Smith y Say, a través de Courcelle-Seneuil., fundador del estudio científico de la economía política en Chile.

En los años sesenta del XIX se crea un sistema monetario y financiero, se desarrolla fuertemente la minería, surge la industria nacional y, a la vez, a nivel de la sociedad civil, una nueva clase capitalista. Pero el desplazamiento del neo-mercantilismo por el liberalismo nunca fue completo. $Y$ tampoco constituyó una victoria conceptual de un sistema sobre otro, pues la disputa entre las dos tendencias fue permanente y las políticas económicas oscilantes entre ambas. Además, los intereses de la elite estaban mejor asegurados por el proteccionismo, que por la nueva tendencia de libre mercado. A este respecto, dice el historiador Sergio Villalobos: "La aplicación de la doctrina liberal implicaba una verdadera aventura, llena de riesgos, que no se sabía como podía concluir". Además, agrega, el Estado quería preservar sus rentas aduaneras, que era su mayor fuente de recursos. Y, por lo demás, ya en la época había surgido la crítica teórica al liberalismo (Federico List, Henry, Chales Carey, etc: $)^{18}$.

Una de las razones que explican la persistencia del proteccionismo, es justamente la integración del país. Las políticas económicas proteccionistas involucran una fuerte intervención del Estado en el sistema productivo y, en definitiva, en la asignación de los recursos. Hay que tener presente que el mercantilismo, cuyo sello es el proteccionismo, es la política económica de los Estados nacionales emergentes. en los siglos XV y XVI ${ }^{19}$. El Estado chileno, a través del proteccionismo, heredero del neo-mercantilismo español del XVIII, recrea esa instancia de la historia de los Estados nacionales. Según Villalobos, la actividad económica de Chile no podía dejarse al laissez-faire, "en un país donde todo estaba por estructurarse y era necesario corregir o acelerar algunos fenómenos económicos que afectaban a la nación" 20 . Esta afirmación es valórica y no puramente descriptiva, por lo cual podría discutirse, pues no está avalada por la política comparada. En los países 
anglosajones, la construcción de la sociedad civil y el Estado va a parejas con el despliegue de una economía de libre mercado. Pero, el caso es que en Chile, el conato de instaurar una economía de esta naturaleza nunca se estabilizó y desarrolló consistentemente en el siglo XIX.

Después de las experiencias liberales de la segunda mitad del XIX, a fines del mismo siglo, el proteccionismo conoce un nuevo renacimiento, guiado por las escuelas nacionalistas e históricas. Según Guillermo Subercaseaux esta tendencia se expande en toda América Latina ${ }^{21}$. Señala que el incremento de la población, el mejoramiento de las comunicaciones y el transporte, el desarrollo de la agricultura y la minería, por una parte, y el desarrollo de la cultura y la vida ciudadana, por otro, permitieron una mejor aptitud para el mejoramiento económico. Estos hechos, junto con la consolidación del sistema político y la "confianza en el derecho" unido a la acumulación de capital, "prepararon el medio para el desarrollo de la industria manufacturera en esta América"22. Ahora bien, afirma Subercaseaux, tal desarrollo no puede lograrse sin una intervención del Estado. En consecuencia, es necesario fortalecer políticas proteccionistas, tal como las que practican los países más avanzados de Europa. Desde el punto de vista teórico, según este autor, ya fines del XIX se había producido "una reacción en la Economía Política en contra del absolutismo libre cambista de la escuela clásica". Esta reacción incluye la aparición del socialismo, que rechaza, pero también una renovación del proteccionismo, que hace suya. Y cita a Henry Carey, Federico List, y, especialmente, a los miembros de la escuela alemana, llamada histórica o realista. de Guillermo Rosher, Gustavo Schmoller y otros, entre los principales autores que influyen en este proceso $0^{23}$.

El lenguaje de la escuela histórica, en su retórica antiliberal y crítica de la economía clásica, supone al Estado nacional, como un agente económico que está por sobre los individuos. La adopción de este modelo, a fines del XIX, le va a conferir al Estado un fuerte protagonismo en el desarrollo económico, como instrumento de la integración nacional. No es el caso, en este ensayo, referirse a ese protagonismo, que se despliega durantes siete décadas del siglo pasado. Solamente debemos recordar que la industrialización del país se hace a partir de las premisas enunciadas por Subercaseaux, así como todas las políticas públicas del welfare state, que el Estado chileno pone en marcha entre los años cuarenta y sesenta.

\section{ESTADO, INTEGRACIÓN Y DEMOCRACIA}

Las actividades clásicas de integración del estado republicano se ejercieron sostenidamente durante todo el siglo XIX. Pero, a nivel de la sociedad se empezaron a operar una serie de cambios, que concluirían por modificar sustancialmente al régimen político, la estructura de la sociedad civil y el sistema económico. El ejercicio de la libertades de pensamiento, opinión y asociación, así

21 Subercaseaux, Guillermo, Historia de las Doctrinas Económicas en América y en especial en Chile; Imprenta Universo, Santiago de Chile, 1924, p. 59.

22 Subercaseaux, Guillermo, op. cit. ; p. 67 y 68.

23 Subercaseaux, Guillermo, op. cit. ; p. 71 y 72. El mismo autor, en su obra principal, Economía Política Teórica, Imprenta Barcelona, Santiago de Chile, 1907, reconstruye el concepto de "Economía nacional", elaborado por la escuela histórica, como distinto al de "Economía individual o privada". La "Economía nacional", nos dice, "sería la entidad u organismo económico especial, formado por el conjunto de Economías individuales y agrupadas en el Estado i unidas entre si por los lazos de las relacionews de crédito i de cambio recíproco i por las relaciones de la Economía individual del Estado mismo (hacienda pública)", p. 22. 
como la difusión de nuevas ideas, sirvieron de hilos conductores de las sucesivas ampliaciones del espacio público, inicialmente monopolizado por una minoría ilustrada de origen conservador. Este fenómeno fue erosionando, en sucesivas oleadas, la hegemonía de la elite original y fundadora.

A mediados del XIX aparecen nuevas elites, que compiten entre si por el poder, desmonopolizando las decisiones públicas y estableciendo las bases de una sociedad compleja y pluralista. Recordemos la aparición de nuevas concepciones de la política, que se reflejan en el desarrollo de los partidos Liberal, Radical y Democrático. Tales concepciones se reflejaron en querellas ideológicas y políticas, que, por ejemplo, dieron como resultado el surgimiento de un pensamiento laico, que tuvo una gran influencia en la formación de una clase media ilustrada no conservadora. Surge así lo que Robert Dahl denomina una poliarquía básica ${ }^{24}$.

Los dos factores anteriores actuaron como las líneas de fuerza que promovieron la aparición de un nuevo sujeto político: el ciudadano democrático, con poderes para tomar parte en el proceso de decisiones políticas. Asimismo, se produjo una fuerte movimiento de publicidad de la deliberación sobre los asuntos públicos, que es una de las características más importantes de la democracia chilena.

De este modo, la cultura política misma, por la persistencia del proceso que se acaba de reseñar, y no obstante mantener sus anclajes en la concepción republicana, evolucionó en forma constante y continua hacia la democracia. Los hechos que marcan y expresan esa evolución, que entraña un giro desde la república, como régimen representativo y moderado, hacia la democracia representativa, si nos reducimos a lo fundamental, son los siguientes:

1. Ampliación del electorado (adopción del voto universal), durante la presidencia radical de Gabriel González Videla (1946-52). Ello significó el acceso de la mujer a la ciudadanía plena.

2. Emergencia de nuevas elites y grupos aspirantes a tener representación política, como expresión de un proceso social y cultural: la configuración del hecho del pluralismo. Pérdida de la homogeneidad de la sociedad civil, solamente por una mayor diferenciación social y la pérdida de hegemonía de la elite fundadora, sino por la aparición de nuevas doctrinas con vigencia en el espacio privado y público: crecimiento de grupos religiosos alternativos a la Iglesia Católica; difusión de ideologías y concepciones diferentes del bien (filosóficas, religiosas y éticas); y demandas de derechos políticos a partir de los géneros y las minorías étnicas, etc.

3. Legitimación y constitucionalización de los partidos políticos, que hasta la Constitución de 1925 existían de facto. Consolidación de un sistema de partidos políticos (como sistema de intermediación entre la sociedad civil y los órganos políticos del Estado). Fortalecimiento de los partidos de masas. Interacción partidista: canalización de opiniones, mediación de demandas de la sociedad civil ante el Estado, formación de cuadros dirigentes, ejercicio del control ciudadano sobre el aparato del Estado y la función pública. Diferenciación de la representación política, que no solamente refleja intereses de electorados locales o sectoriales, sino también concepciones ideológicas acerca del bien público.

4. Desarrollo, durante los años 20 a 70, de políticas públicas sociales, referidas a la promoción de la igualdad y que incluyeron las aplicación en Chile de concepciones socialdemócratas y 
económicas del welfare state. Substitución de esas políticas, a partir de los años 70, por un modelo de economía de mercado, fuertemente desrregulada, con énfasis en los equilibrios macroeconómicos y la apertura a la competencia de los mercados internacionales.

En el nuevo contexto, las líneas de continuidad siguen operando. Y así lo expresa la plena vigencia de los esenciales constitucionales establecidos más arriba. En consecuencia, el rol integrador clásico del Estado decimonónico sigue vigente. No obstante, esa vigencia se despliega ahora en una condiciones nuevas, marcadas por los cambios políticos ya expuestos y aquellos que son su correlato en el ámbito de la sociedad civil. Estos últimos tienen, al menos, tres características relevantes: un mayor grado de diversificación de la sociedad, acompañado de niveles superiores de autonomía respecto del poder político y su índole abierta y pluralista. En el pasado, en contraste, la sociedad era mucho más homogénea, dependiente de la acción estatal y cerrada. Este cambio se experimenta porque la sociedad misma nos ofrece más oportunidades, mas espacios coherentes y articulados que recorrer, menos dependencia del poder político, mayor libertad para tomar decisiones por cuenta propia. De este modo, el cambio operado a nivel de la sociedad, por su solo despliegue, ha rearticulado las relaciones entre la esfera privada y la esfera pública.

En el ámbito económico, muchas actividades que eran realizadas subsidiariamente por el Estado, son asumidas por el sector privado. Este es un reflejo del hecho más general que se acaba de reseñar. De este modo, es un hecho esencial de este proceso que lentamente la sociedad civil ha asumido la responsabilidad de hacerse cargo de la producción de bienes y servicios, e incluso de la administración de aquellos que en el pasado, por su status de monopolios naturales, se consideraba que debían estar administrados por el Estado. Sobre estas bases, la economía chilena se abre al exterior, a un mundo globalizado.

De este modo, el nuevo contexto de la tradicional función integradora del Estado es menos simple que en el pasado, porque incluye las siguientes variables: la democracia, la sociedad heterogénea, compleja y pluralista y la globalización.

Por de pronto, los cambios han obligado al Estado a readecuar su estructura y sus funciones a una nueva realidad. A esta readecuación se la denomina modernización. La esfera estatal puede hoy día, más que en el pasado, ser en cierta medida "cosificada". Este es un fenómeno inverso a la idealización del Estado que es característico de fines del XVIII y comienzos del XIX; Y esto es posible porque el Estado, ese "dios" con minúscula de Hobbes, también ha sido sacudido por el vendaval de la secularización. El Estado ha sido desidealizado y desacralizado Por eso, hoy empieza a imponerse la tendencia a definirlo como una "agencia" de los intereses comunes o públicos. En esta perspectiva, el núcleo duro del Estado contemporáneo está constituido por una cantidad muy reducida de posiciones de autoridad o "agentes públicos": el Presidente de la República, Ministros, Subsecretarios, Directores Generales, Superintendentes, Intendentes, Gobernadores, Parlamentarios, Alcaldes, Concejales, J ueces y Mandos militares. A estos agentes públicos se le pide: estabilidad gubernativa, capacidad de gobierno (gobernabilidad), eficiencia para responder a las demandas de los gobernados (responsiveness) y accountability. Estas dos últimas características quieren decir que la sociedad civil le exige a los agentes públicos: que respondan a las demandas comunes de la sociedad civil con eficiencia y que den cuenta permanente de las actividades que desarrollan en el desempeño de sus funciones. 


\section{Función integradora de la democracia representativa como forma política}

Hoy día, raíz de la reaparición de antiguas nacionalidades, que reivindican derechos políticos especiales -incluyendo la secesión- al interior de un Estado nacional, el tema de la integración se plantea de un modo enteramente diferente. A través de este ensayo hemos expuesto la función tradicional del Estado como integrador de la nacionalidad chilena. También hemos dejado entrever que mientras en Chile, como en general en América Latina, el Estado es un factor determinante en la construcción de la nacionalidad chilena. En otras latitudes el proceso es distinto, como es el caso de comunidades racialmente homogéneas que junto con organizarse como Estado construyen una nación, imponiéndose a otros grupos étnicos; otro caso diferente es aquel de comunidades étnicas no dominantes que se auto-identifican como una nación, y que persisten en el proyecto de darse a si mismas la forma estatal (vascos). Intento que puede tener distintos desenlaces, como lo demuestra la historia de los movimientos nacionalistas durante los siglo XIX y XX. En consecuencia, al menos podemos enumerar tres tipos diferentes de construcción de la integración nacional.

Es claro que el modelo latinoamericano es insuficiente desde el punto de vista de la democracia. Durante el siglo XIX, la construcción del Estado latinoamericano, y su correlato, las distintas nacionalidades latinoamericanas, entendieron la integración como absorción de todas las comunidades étnicas aborígenes en una unidad superior, la nación latinoamericana correspondiente. En este proceso, siguiendo a Renan, operó fuertemente una estrategia de desidentificación de esas comunidades étnicas de sus propias raíces, una amnesia sobre sus orígenes, su lengua, su religión y su historia. Esa estrategia exigió, por parte del Estado fundador, un uso intenso de su poder coercitivo. La razón de Estado, que además estaba unido a la Iglesia, justificó la represión de las manifestaciones externas de tales comunidades, o sea, de sus formas culturales. La asimilación a una cultura dominante y hegemónica, constituyó el eje central de una política de Estado largamente sostenida hasta fines del siglo XX.

La filos ofía política contemporánea, y especialmente la teoría democrática, se ha hecho cargo del movimiento de reivindicaciones de las comunidades étnicas. En el caso particular de América Latina, y especial de Chile, la primera cuestión que se levanta es si acaso la sociedad civil es multiétnica y, por lo mismo, multicultural. La respuesta es afirmativa, incluso para países, como Chile y Argentina, que han cultivado su imagen de homogeneidad racial y cultural. La verdad es que este es un hecho es incontrovertible. La segunda cuestión que debe proponerse se refiere al grado de expresión que tiene esa realidad. Y tanto la investigación empírica, como los movimientos reivindicacionistas indígenas, nos muestran que en el caso chileno, las instituciones y las prácticas democráticas son inconsistentes con el pluralismo de la sociedad civil. Ellas, en efecto, solamente permiten una expresión limitada de algunas minorías.

No hay duda que una identidad nacional provee las bases para la confianza (trust) entre los diferentes grupos de la sociedad, y por lo mismo, para facilitar los compromisos entre intereses distintos e incluso contrapuestos. Pero, no hay razones suficientes para sostener que ello no pueda conseguirse también sobre las bases de un sentido de pertenencia un sistema político. Cuando este sentido produce una identificación con las instituciones y prácticas principales de un sistema, es obvio que ellas son el mejor medio para resolver disputas de intereses. 
Algunos sostienen que una política del bien común solamente se puede alcanzarse si existe una identidad nacional. Se trata de una tesis dicutible. Es intuitivamente plausible que un sentido de pertenencia a un sistema político es siempre necesario para construir una política del bien común, y que muchas veces ella es anterior y más fundamental que la adescripción a una identida nacional.

También se puede responder de un modo similar a la tesis de que las políticas redistributivas están condicionadas a la previa existencia de una identidad nacional. Las políticas redistributivas, fundadas en la justicia social, dependen de principios de justicia social. Y estos, a su vez, más bien integran el marco institucional, o sea, se refieren al sentido de pertenencia a un sistema político.

\section{Función integradora de los consensos políticos y la deliberación pública}

Ahora bien, esta nueva conceptualización del Estado da origen a nuevas modalidades de integración. Por de pronto, la democracia representativa, para generar gobiernos estables y capaces de darle gobernabilidad al país, deben sustentarse en grandes mayorías. Y estas, a su vez, son el resultado de consensos entre distintas elites con ascendiente en el electorado. De este modo, la competencia por el gobierno, en gran medida depende de procedimientos que garanticen esos acuerdos y permitan la constitución de gobiernos estables.

Por otra parte, la eficiencia del aparato gubernativo, requiere la inclusión de una elite no política: la tecnocracia. La capacidad para responder a la sociedad civil, depende de modo creciente de la eficiencia para resolver problemas públicos complejos a través de conocimientos. La inserción de la tecnocracia en el proceso de decisiones públicas, y su legitimación democrática, forma parte de los problemas de la modernización.

Los gobiernos estables, respondientes y transparentes, crean en torno suyo consenso, aceptación. Y, en este sentido, tienen un efecto de integración. Se trata, como es obvio, de un nivel volátil de integración. Pero, a la vez, es la modalidad de integración propia del gobierno por la discusión 0 el debate, que caracteriza a la democracia deliberativa. En definitiva, si atendemos a los instrumentos que garantizan el ejercicio de la accountability -fiscalización parlamentaria y control ciudadano a través medios de comunicación plurales y diversificados y grupos de acción y otros, surgidos del derecho de asociación- podemos advertir que ellos cooperan a crear opinión pública, y que, tanto el proceso de gestación de la misma, como su existencia, constituyen uno de los más potentes factores de integración política de las sociedades contemporáneas.

De este modo, podemos decir que las normas procedimentales de la democracia, así como los nuevos instrumentos jurídicos y factuales de control democrático del poder político, ejercen funciones de integración, en la medida que está a disposición de los ciudadanos para crear consensos y acuerdos.

No obstante, en la perspectiva de una democracia sustantiva, el gran factor integrador de una sociedad pluralista, a nivel de las normas, son los principios de justicia política que la rigen. Tal como lo ha formulado J ohn Rawls, esos principios son tales cuando permiten y promueven la cooperación entre individuos que tienes concepciones distintas e incluso contradictorias del bien (filosóficas, religiosas y morales). Si el Estado contemporáneo ha avanzado en la dirección de adoptar principios de justicia política que permiten esa cooperación, ha sido a costas de renunciar a adoptar "una" de las concepciones del bien disponibles como la ideología que articula sus valores, leyes e instituciones. 
La integración, en el largo plazo, en la medida que las sociedades son abiertas y pluralistas, no solamente plantea desafíos a nivel de los procedimientos para llegar a acuerdos o consensos, sino a nivel de la justicia política. Es claro que estas desafíos están relacionados con la cultura en general y la cultura política en particular, porque es previsible que los contenidos culturales mismos se vean sujetos a una revisión. En esta perspectiva, de algún modo, la identidad nacional se verá expuesta a pruebas, no solamente por la incorporación de factores de heterogeneidad interna (y pérdida de homogeneidad), sino también por su exposición a los fenómenos de la globalización.

El desarrollo democrático ha traído consigo un mayor dinamismo a las demandas por igualdad social. En este orden, los problemas de las altas tasas de pobreza, déficit educacional y falta de cobertura de salud, se han transformado en demandas insatisfechas por el sistema político y económico.

La respuesta del Estado a estas demandas constituye uno de los factores más importantes de integración social. Los esfuerzos del Estado democrático involucran una actividad redistributiva, generalmente aprobada a través de consensos entre el gobierno y la oposición, para financiar políticas públicas en los campos señalados. Esta actividad tiene por fin ampliar la igualdad de oportunidades a todos los chilenos. En la medida que estas políticas son eficaces, o sea, cumplen con su finalidad, sus efectos integradores son muy fuertes. Se trata de una integración por la vía del ascenso social y la solidaridad, donde las relaciones de reciprocidad entre los miembros de la sociedad civil es explícita y evidente.

\section{CONCLUSIÓN}

Las funciones clásicas del Estado en el ámbito de la integración siguen vigentes, pero han sido modificados profundamente en los regímenes democráticos. La integración siempre ha sido entendida primariamente como la unidad nacional, y, por lo mismo, presupone la construcción de una nacionalidad. Desde la democracia, en cambio, la integración apunta a la cooperción y la solidaridad en una sociedad abierta y pluralista. De este modo, la función de integración del Estado democrático tiene como punto de partida la pertenencia de la comunidad al sistema político, más que a la comunidad histórico-cultural. Este tipo de pertenencia permite la integración de minorías que conservan su identidad, pues, en definitiva, se, funda en el consentimineto. Y respecto de las minorías, en la democracia la integración de las minorías, en una comunidad políticamente organizada, no pasa ni por el olvido de la propia identidad histórica, ni por su absorción o inclusión coercitiva en una mayoría dominante. 